\title{
Isolation of Cancer Epithelial Cells from Mouse Mammary Tumors
}

Sara Johnson, Hexin Chen ${ }^{\star}$ and Pang-Kuo Lo

Biological Sciences Department, University of South Carolina, Columbia, USA

*For correspondence: $\underline{\text { hchen@biol.sc.edu }}$

[Abstract] The isolation of cancer epithelial cells from mouse mammary tumor is accomplished by digestion of the solid tumor. Red blood cells and other contaminates are removed using several washing techniques such that primary epithelial cells can further enriched. This procedure yields primary tumor cells that can be used for in vitro tissue culture, fluorescence-activated cell sorting (FACS) and a wide variety of other experiments (Lo et al., 2012).

\section{Materials and Reagents}

1. Bovine serum albumin (Sigma-Aldrich, catalog number: A9576)

2. Sterile Dulbecco's phosphate buffered saline (PBS) (Sigma-Aldrich, catalog number: D8537)

3. $\mathrm{NH} 4 \mathrm{Cl}$ solution (StemCell Technologies, catalog number: 07850)

4. Scalpel or Razor Blade

5. EasySep Negative Selection Kit (StemCell Technologies, catalog number: 19757)

6. Accutase (ITC, catalog number: AT104)

7. Collagenase (StemCell Technologies, catalog number: 07912)

8. Penicillin/Streptomycin (Life Technologies, Invitrogen ${ }^{\mathrm{TM}}$, catalog number: 10378-016)

9. Dulbecco's Modified Eagle Medium/F12 (Sigma-Aldrich, catalog number: D8437)

\section{Equipment}

1. Swing bucket centrifuge

2. Incubated shaker

3. EasySep Magnet (StemCell Technologies, catalog number: 18000)

4. Sterile Nylon Mesh 40 micrometer cell strainer (BD Biosciences, Falcon ${ }^{\circledR}$, catalog number: 352340)

5. $50 \mathrm{ml}$ conical tube 


\section{Procedure}

1. Sacrifice or anesthetize the animal and restrain the animal by pinning its feet into a foam surface using pushpins. Make a parallel incision from the base of the tail up to the neck along the mouse's abdomen, careful not to puncture the peritoneum. Gently pull back the skin and pin it to the foam surface to reveal the tumor(s). Cut the tumor free from the skin and the body, carefully removing as much excess tissue surrounding the tumor as possible.

2. Store the harvested tumors in serum-free DMEM/F12 medium on ice until the digestion procedure.

Notes: Tumors should be digested as soon as possible after removal. We would not recommend more than $1 \mathrm{~h}$ on ice.

3. In a $10 \mathrm{~cm}$ Petri dish, mince the tumor (0.5-1.0 $\mathrm{mg}$ or more dependent on experimental needs) into 1-2 $\mathrm{mm}$ pieces using a razor or scalpel and place into a $50 \mathrm{ml}$ conical tube. This should be performed in a biological cabinet at room temperature. A small amount of digestion medium can be added to the tumor to make mincing easier. It is not essential to mince the cells on ice. The tumors should be minced efficiently but not in a rush so as to leave pieces that are too large.

4. Add the digestion medium to the $50 \mathrm{ml}$ conical tube in a 10:1 ratio to the volume of the tumor such that there is approximately ten times more digestion medium in the tube than tumor.

5. Place the tube securely onto an incubated shaker in an inclined position such that the medium and tumor are constantly mixing. Digest the minced tumors for $3-5 \mathrm{~h}$ at $37{ }^{\circ} \mathrm{C}$. Though some pieces of tumor may remain, check that most of the tumor has been dissolved for thorough digestion.

6. Dilute the digested mixture with DMEM/F12 containing $0.2 \%$ BSA at a $1: 1$ ratio with the digested tumor. This will lead to a doubling of the volume.

7. Filter the mixture through a 40 micrometer sterile nylon mesh cell strainer into another sterile $50 \mathrm{ml}$ conical tube. From this point forward, keep cells on ice at all times except during centrifugation and digestion with Accutase.

8. Spin down the filtered cells at $200 \times g$ for 5 min and remove supernatant.

9. Resuspend the cells in an appropriate volume of DMEM/F12-0.2\% BSA to wash ( 1 ml per $\mathrm{ml}$ cell pellet).

10. Spin down the cells again at $200 \times g$ for $5 \mathrm{~min}$ and remove supernatant.

11. In order to lyse red blood cells contaminating the pelleted cells, mix $4 \mathrm{ml} \mathrm{NH}_{4} \mathrm{Cl}$ and $1 \mathrm{ml}$ PBS-1.0\% BSA (4:1 ratio) first and use this mixture to resuspend the pellet (these calculations are appropriate for a pellet that occupies a volume of approximately $5 \mathrm{ml}$. 
The amount of $\mathrm{NH}_{4} \mathrm{Cl}$ and PBS-1.0\% BSA should be adjusted for the size of the pellet with the ratio remaining $4: 1$ ). Leave the cells in the solution for $2-3 \mathrm{~min}$ at room temperature depending on the amount of RBC contamination, which can be determined by the presence of red color. If the tumor is well-vascularized and the pellet is very red in color, repeat the procedure until the red color diminishes.

12. Spin down the cells at $200 \times g$ for $5 \mathrm{~min}$ and remove supernatant.

13. Wash the cell pellet in DMEM/F12-0.2\% BSA and spin down cells. Repeat this step several times until the supernatant becomes clear.

14. If cells are clumped together during medium washing, digest the $1-2 \times 10^{6}$ cells with $1 \mathrm{ml}$ Accutase for $10 \mathrm{~min}$ at $37^{\circ} \mathrm{C}$ to dissociate aggregated cells.

15. Add $2 \mathrm{ml} \mathrm{DMEM/F12-0.2 \%} \mathrm{BSA} \mathrm{per} 1 \mathrm{ml}$ Accutase and mix by pipetting to neutralize the reaction of the enzyme.

16. Spin down cells at $200 \times g$ for 5 min and wash cells using PBS.

17. Remove supernatant and suspend in an appropriate volume of PBS for the pellet size $(\sim 1$ $\mathrm{ml}$ per $\mathrm{ml}$ of pellet present). Store cells on ice until isolation.

18. Lineage marker negative $\left(\mathrm{Lin}^{-}\right)$epithelial cells from mammary glands can then be isolated using the EasySep negative selection kit according to the manufacturer's instructions. This will remove unwanted cells by targeting these cells with antibodies against non-epithelial cells. The Lineage marker positive (Lin+), non-epithelial cells are attracted to the magnet required for use with the EasySep negative selection kit and desired cells remain free to be collected. This yields a purified epithelial sample for use in other experiments.

19. Isolated cells can be kept on ice for at least $1 \mathrm{~h}$ until they are used for experimental analyses. Isolate cells can also be kept in appropriate cell freezing medium and then stored at $-80^{\circ} \mathrm{C}$ or in liquid nitrogen for long-term storage.

\section{Recipes}

1. Tumor Digestion Medium (50 ml)

$25 \mathrm{ml}$ Accutase

$50 \mathrm{mg}$ Collagenase

$0.5 \mathrm{ml}$ 100x Penicillin/Streptomycin

$24.5 \mathrm{ml}$ Dulbecco's Modified Eagle Medium/F12 


\section{Acknowledgments}

This protocol was first described in our manuscript Lo et al. (2012). This work was supported by the Elsa U. Pardee Cancer Foundation grant (B94AFFAA), the American Cancer Society Research Award (RSG-10-067-01-TBE) to HC and NIH grant (3P20RR017698-08) to HC and QW.

\section{References}

1. Lo, P. K., D. Kanojia, X. Liu, U. P. Singh, F. G. Berger, Q. Wang and H. Chen (2012). CD49f and CD61 identify Her2/neu-induced mammary tumor-initiating cells that are potentially derived from luminal progenitors and maintained by the integrin-TGFbeta signaling. Oncogene 31(21): 2614-2626. 